\title{
Correction to: Morphological and phylogenetical analysis reveals that a new tapeworm species (Cestoda: Hymenolepididae) from whooper swan belongs to Cloacotaenia not Hymenolepis
}

\author{
Zhijun Hou $^{1} \cdot$ Lei Han ${ }^{1} \cdot$ Ying Sun $^{1} \cdot$ Dongdong Shen $^{1} \cdot$ Zhiwei Peng $^{1} \cdot$ Lixin Wang $^{1}$ • \\ Qian Zhai ${ }^{1} \cdot$ Yanqiang Zhou $^{1} \cdot$ Yaxian $^{\mathrm{Lu}^{1}} \cdot$ Liwei Teng $^{1} \cdot$ Hongliang Chai $^{1}$
}

Published online: 6 October 2021

(C) Northeast Forestry University 2021

\section{Correction to:}

J. For. Res. (2020) 31(6):2581-2587

https://doi.org/10.1007/s11676-019-01036-2

After publication of this article, it was brought to our attention that the legend to Figure 1 did not state that Figure 1d was adapted from Figure 1d of Makarikov and Tkach (2013). In addition, Makarikov and Tkach (2013) should have been cited in the methods section.
Makarikov, A. and Tkach, V. Two new species of Hymenolepis (Cestoda: Hymenolepididae) from Spalacidae and Muridae (Rodentia) from eastern Palearctic. Acta Parasitologica, vol. 58, no. 1, 2013, pp. 37-49. https://doi.org/10. 2478/s 11686-013-0115-0

Publisher's Note Springer Nature remains neutral with regard to jurisdictional claims in published maps and institutional affiliations.

The original article can be found online at https://doi.org/10. 1007/s11676-019-01036-2.

Zhijun Hou

houzhijundz@163.com

Liwei Teng

tenglw@gmail.com

Hongliang Chai

17758625@163.com

1 College of Wildlife Resource, Northeast Forestry University, Harbin 150040, People's Republic of China 